\title{
COMPARATIVE STUDY ON CONVENTIONAL BITUMEN MIX AND GILSONITE MODIFIED BITUMEN MIX
}

\author{
AADIL AHMED BHAT \& KSHITIJ JASSAL \\ ${ }^{I} P G$ Student, Department of Civil Engineering, Chandigarh University, NH-95, Gharuan, Distt Mohali, Punjab, India \\ ${ }^{2}$ Assistant Professor, Department of Civil Engineering, Chandigarh University, NH-95, Gharuan, Distt Mohali, Punjab, India
}

\begin{abstract}
In a bituminous concrete mix, bitumen is used as an adhesive or binder to bind the aggregate ingredients of the mix. Bitumen has a significant effect on the performance of the asphalt mix, depending upon the quality and type of bitumen used. To improve the performance of bitumen and bituminous concrete mix, the use of modifiers is increasing worldwide. Different kinds of modifiers used to increase the performance of bitumen and its mix are ethylene vinyl acetate, styrene buta Diene, Bakelite and crumble rubber, etc. In this work, Gilsonite is used as a part of bitumen and a modifier to improve the performance of asphalt mix. The main aim of this work is to study the effect of Gilsonite on the various properties of a bituminous concrete mix and to compare the results with the conventional bituminous mix. Gilsonite contains a large number of polar compounds and resins, so it is easily compatible with bitumen and also helps in enhancing its performance. An experimental study is conducted to find the effect of Gilsonite on the various properties of the mix such as bulk specific gravity of mix (GM), air voids (VA), voids in mineral aggregates (VMA), voids filled by bitumen (VFB), Marshall stability value and flow value and compare them with the conventional properties of the mix by conducting volumetric analysis and marshall stability test. In the present study, the Gilsonite is doped in bitumen at the percentages of $2.5 \%, 5 \%, 7.5 \%, 10 \%, 12.5 \%, 15 \%$ and $17.5 \%$. The results showed that the addition of Gilsonite as a modifier in bitumen results in an increase in softening point, a decrease in penetration increase in Marshall stability, and a decrease in flow value of bituminous concrete mix.

KEYWORDS: Hot Mix Asphalt, Gilsonite, Optimum Bitumen, Pavement, Marshal Stability Test
\end{abstract}

Received: Jun 08, 2020; Accepted: Jun 28, 2020; Published: Sep 16, 2020; Paper Id.: IJMPERDJUN20201269

\section{INTRODUCTION}

In India the most commonly used pavement material for flexible pavements hot mix asphalt. The main constituents of hot mix asphalt are bitumen, aggregates, and filler. The performance of asphalt mainly depends upon the nature and quality of aggregate used. The aggregates used for the Asphalt concrete may be either siliceous or argillaceous which both shows the different response in the performance of bituminous concrete. The performance of bituminous concrete also depends upon nature and chemical composition of bitumen and the affinity of bitumen towards the aggregates. The bonding between the bitumen and aggregates is mainly due to polar components in bitumen and Vander Waals forces. In bitumen, the aromatic hydrocarbons show less attraction towards the aggregates the asphaltenes and resins. In addition to the functional groups that have a stronger affinity towards aggregates are Carboxylic acids, Sulfoxides, Ketones, phenols, and Nitrogen compounds [8]. In recent times, various modifiers are used to increase the binding affinity, stability, durability, and performance of bitumen and its mix. In this study, Gilsonite is used as a part of bitumen or adhesive to enhance the performance of the mix. 
Gilsonite is bright black asphalt that can be easily crushed into powder form. When the bitumen comes out from the ground through cracks and fissures and gets solidified on the ground surface (without forming Asphalt Lake). The solid material thus formed is called as Gilsonite/ natural bitumen /Asphaltite. Gilsonite is a natural hydrocarbon, high in asphaltenes and nitrogen compounds [9] and is fully compatible with bitumen. Gilsonite forms a true and stable solution to dissolving in the bitumen. Gilsonite can be added to the hot mix either by pre dissolving the Gilsonite in hot bitumen before the addition of bitumen to the mix (Wet Method) or by adding the Gilsonite powder with the aggregates (Dry Method). In this work, the wet method of mixing is used to mix the Gilsonite in the bitumen.

In this method, the bitumen is heated $20 \mathrm{C}$ to $30 \mathrm{C}$ above the softening point of the bitumen and Gilsonite powder is mixed into the bitumen and is stirred continuously to ensure the proper mixing for better results. From the previous studies, it has been found that the addition of Gilsonite to bitumen results in lowering the penetration value, increase in softening point, increase in softening point of bitumen and also it helps in increase in Marshall Stability and decreases the flow value [2]. From the previous study, it was revealed that the presentation and temperature weakness of Gilsonite and styrene butadiene styrene changed black-top covers. The outcomes got demonstrated that the expansion of Gilsonite and styrene butadiene styrene in blend increment the conditioning point and thickness of folios. It was likewise discovered that the entrance grade diminishes with the expansion in the Gilsonite and styrene butadiene styrene content in the blend [4]. The impact of Gilsonite changed bitumen on the volumetric properties and steadiness parameters of the blend. It was discovered that the expansion of Gilsonite expands the Marshall steadiness of blend. Increment in the Gilsonite content leads to a decline in the black-top mass explicit gravity. Increment of Gilsonite content prompts increment noticeable allaround voids of the blend. With the expansion of Gilsonite content in the bitumen, the stream esteem diminishes and the estimation of voids in mineral total increments [10]. The impact of Gilsonite on dampness affectability utilizing two distinct sorts of totals, for example, siliceous totals and lime totals, found that expansion of Gilsonite improves the dampness affectability of blends containing siliceous totals as they have higher TSR values than blends having lime totals having lower TSR values [5]

It was examined that expansion of $4.6 \%$ of Gilsonite by weight of bitumen expands the Marshall dependability of blend. Expansion of Gilsonite builds the black-top blend obstruction against the pliable burdens instigated in it because of traffic load. It was likewise discovered that the expansion of Gilsonite to black-top blends lessens the dampness affectability. Inflexible modulus test the black-top example changed with Gilsonite shoes the better execution comparative with unmodified examples [2]. It was found that a critical increment in the mechanical quality and firmness under monotonic and dynamic stacking was seen when the bitumen is changed with Gilsonite. This expansion is fundamentally a direct result of the increment in firmness created by the black-top when interacting with the Gilsonite. The Gilsonite produced an increment in the thickness, mellowing point, and execution evaluation of bitumen at high assistance temperatures and a critical abatement in the entrance reviewing. It was additionally discovered that the blending of Gilsonite in the hot blend black-top by wet and dry procedures influences the conduct of Gilsonite as a modifier. It was discovered that the blending of Gilsonite by wet procedure gives better outcomes [8]An expansion in the solidness under cyclic stacking in the obstruction against dampness harm in freeze-defrost cycles and the opposition against changeless disfigurement. Also, these specialists detailed that the blends changed with Gilsonite decreased the optimum asphalt content in the design of the mixture by $1 \%$, diminishing the creation cost of the black-top blend [6] This material to deliver a black-top solid blend and assessed its properties under monotonic and dynamic stacking. The outcomes got from their investigation exhibited that the black-top blends altered with Gilsonite utilizing a wet procedure, i.e., adding Gilsonite to 
the black-top concrete, created stiffer black-top solid blends, prompting the end that these blends would perform well in warm atmospheres.

The Marshall Strength and solidness estimations of the changed blends were more noteworthy for any level of black-top and Gilsonite contrasted and the reference blend, i.e., without Gilsonite. The strong moduli of the altered blends were better than those getting for the reference blends, and more noteworthy increments were acquired when the temperature of the test expanded. These outcomes demonstrated that Gilsonite, as a black-top modifier, can be utilized to improve the firmness qualities and opposition against lasting mis happenings of blends that are utilized in warm atmospheres [11].

\section{MATERIALS \& EXPERIMENTAL PROCEDURES}

\section{Material}

\section{Aggregates}

Crushed Argillaceous and siliceous aggregates were used in this study which is obtained from the lab of Chandigarh University. The gradation of aggregates used is Grade II as per MORTH specification for bituminous concrete. The gradation of aggregates used in the preparation of the bituminous is given in Fig 1.

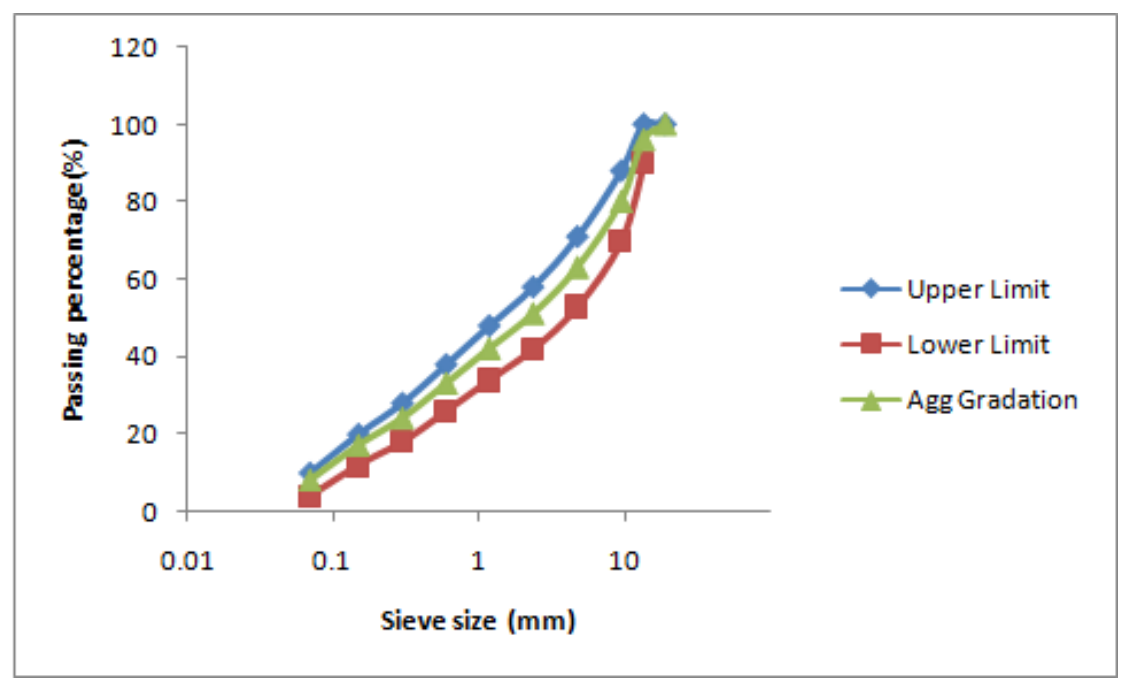

Figure 1: Gradation Curves.

Table 1: Physical Properties of Aggregates

\begin{tabular}{|c|l|c|c|c|}
\hline Sr. No & \multicolumn{1}{|c|}{ Property } & Result (\%) & Specifications for BCM & Test Method \\
\hline 1 & Abrasion Value & 23.22 & Max 30\% & IS: 2386 Part 5 \\
\hline 2 & Impact Value & 16.37 & Max 24\% & IS :2386 Part 4 \\
\hline 3 & Crushing Value & 18.80 & Max 30\% & IS :2386 Part 4 \\
\hline 4 & Elongation and flakiness index & 27.42 & Max 35\% & IS 2386 Part 1 \\
\hline 5 & Specific Gravity of coarse aggregates & 2.68 & $2.5-3 \%$ & IS: 2386 Part 3 \\
\hline 6 & Water absorption of coarse aggregates & 0.4 & $2 \%$ & IS: 2386 Part 3 \\
\hline 7 & Specific gravity of fine aggregates & 2.48 & $2.5-3 \%$ & IS:2386 Part 3 \\
\hline 8 & Water absorption of fine aggregates & 1.47 & $2 \%$ & IS :2386 Part 3 \\
\hline
\end{tabular}

\section{Bitumen}

The bitumen used in the study is VG-40 obtained from the plant near Chandigarh University. The various physical properties of bitumen are given in the table. 
Table 2: Physical Properties of Bitumen

\begin{tabular}{|c|l|c|c|c|}
\hline S. No & \multicolumn{1}{|c|}{ Physical Properties } & Results & Specification & Test Method \\
\hline 1 & Penetration $@ 25^{\circ} \mathrm{C}, 0.01 \mathrm{~mm}$ & 41.5 & $35-50$ & IS 1208-1978 \\
\hline 2 & Ductility cm & $89 \mathrm{~cm}$ & $>75 \mathrm{~cm}$ & IS 1208-1978 \\
\hline 3 & Softening Point & $54^{0} \mathrm{C}$ & $>47{ }^{0} \mathrm{C}$ & IS 1203-1978 \\
\hline 4 & Specific Gravity & 1.02 & $0.97-1.05$ & IS 1202-1978 \\
\hline
\end{tabular}

\section{Gilsonite}

It is a natural hydrocarbon, high in asphaltenes, and other nitrogen components that are fully compatible with the bitumen. The Gilsonite is obtained from Indian mart. The Gilsonite powder used for modification of bitumen is passed through $0.2 \mathrm{~mm}$ sieve and the percentage of Gilsonite passed through the sieve is used in this work. The various physical properties of Gilsonite are given in the table:

Table 3: Physical Properties of Gilsonite

\begin{tabular}{|c|l|c|}
\hline S. No & \multicolumn{1}{|c|}{ Physical Properties } & Specifications in \% \\
\hline 1 & Specific gravity @ 25 $\mathrm{c}\left(\mathrm{gm} / \mathrm{cm}^{3}\right)$ & 1.05 \\
\hline 2 & Solubility in $\mathrm{CS}_{2}(\%)$ & 99 \\
\hline 3 & Solubility in TCE $(\%$ & 96 \\
\hline 4 & Penetration @ $25^{0} \mathrm{c}(0.01 \mathrm{~mm})$ & 0 \\
\hline 5 & Moisture content $(\%)$ & 0 \\
\hline 6 & Hydrogen content $(\%)$ & 6.43 \\
\hline 7 & Nitrogen content $(\%)$ & 0.77 \\
\hline 8 & Oxygen content $(\%)$ & 1.59 \\
\hline 9 & Sulphur content $(\%)$ & 3.09 \\
\hline
\end{tabular}

\section{Methods}

\section{Doping of Bitumen by Gilsonite}

For the present study, the doping of bitumen by Gilsonite is done at the percentages of 2.5, 5, 7.5, 10, 12.5, 15, and 17.5\% by weight of Gilsonite. It can be done by following two Methods: (a) Dry Method(b)Wet method

Wet Method of doping is used in the study. In the wet method, the Gilsonite is added to the bitumen before mixing with aggregates at a temperature of $160^{\circ} \mathrm{C}-170^{\circ} \mathrm{C}$ and bitumen is continuously stirred to ensure the proper mixing of Gilsonite for better performance.

\section{Presenting the Mix Design (Marshall Test)}

Marshall Test is conducted as per ASTM D 1559 standards, to evaluate, compare, and to find the optimum bitumen contents of bitumen and Gilsonite. Marshall Method is an experimental method of mix design and is the most popular and commonly used method for paving jobs. The main aim of this method is to design the most economical method with high durability and stability. In this test, the optimum bitumen content of the mix ix calculated. There are different criteria for calculating the $\mathrm{OBC}$ of the mix. In this work, the $\mathrm{OBC}$ of the mix is taken as the average of the bitumen contents with max Marshall Stability, max bulks specific gravity, and the bitumen content corresponding to 4\% air voids. After this, the Marshall samples are prepared as per ASTM D 1559 standards and for compressing of samples marshal hammer is used to g preparing the mix.ive 75 blows on each side of the sample. The aggregates used were kept in the oven before preparing the samples. 


\section{Volumetric Calculations}

In volumetric calculations, various volumetric properties of the mix such as theoretical maximum specific gravity of mix, the bulk specific gravity of mix, percent air voids, voids filled by mineral aggregates, voids filled by bitumen are calculated. After the testing of the samples, the Marshall stability and flow values are noted down from the Marshall testing machine.

\section{RESULT AND DISCUSSION}

\section{Marshall Test Results}

The marshal samples are prepared and tested as per ASTM standards to find the optimum bitumen and Gilsonite content. The various conventional samples (without Gilsonite) are prepared with bitumen contents of 4.7\%, 5.2\%, 5.7\%, 6.2\%, and $7.2 \%$ of bitumen contents. Three samples are prepared for each percentage. From the results of the Marshall Test for these conventional samples, it has been found that the optimum bitumen content for this bituminous concrete mix with grade 2 is 5.7 (Min 5.4 as per MORTH Specifications). According to the OBC (5.7) obtained for these conventional samples, bitumen Gilsonite mixtures with $0 \%, 2.5 \%, 5 \%, 7.5 \%, 10 \%, 12.5 \%, 15 \%$ and $17.5 \%$ of Gilsonite by weight of OBC are prepared. The conventional samples without Gilsonite are used to control the results. These modified samples are tested as per Marshall Procedure. From the results of the Marshall Test for these Gilsonite modified samples it has been found that the flow value of these samples decreases with the increase in Gilsonite content when compared with the conventional one. The results of the flow values are shown in fig. 1.

According to the results of fig.2, it has been found that the Marshall stability of the mix increases with the increase in Gilsonite content. The maximum marshal stability has been found at 15\% of Gilsonite content. By investigating the variation of voids in mineral aggregates with Gilsonite content, it has been found that the VMA increases in the mix with the increase in the Gilsonite content. From the results of fig. 4, it has been found that the percent air voids increase with the increase in the Gilsonite content in the mix. This could be the reason for the decrease in the bulk specific gravity of the bituminous concrete mix. Minimum air voids are found at $15 \%$ of Gilsonite content. The test results of the variation of voids filled by bitumen with Gilsonite content is shown in fig.5. It has been found that VFB increases with the increase in Gilsonite content in the mix. It has also been found that the $70 \%$ voids filled by the bitumen are obtained at $15 \%$ of Gilsonite content.

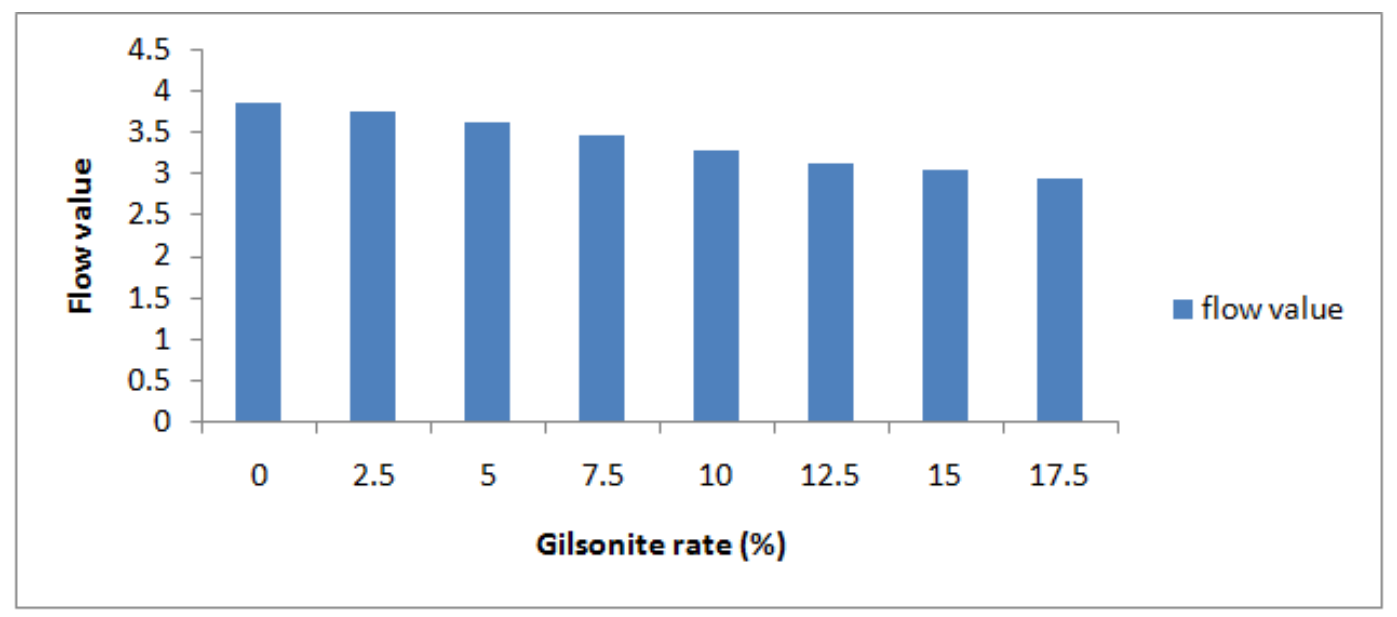

Figure 2: Variation of Flow Value with Gilsonite Content. 


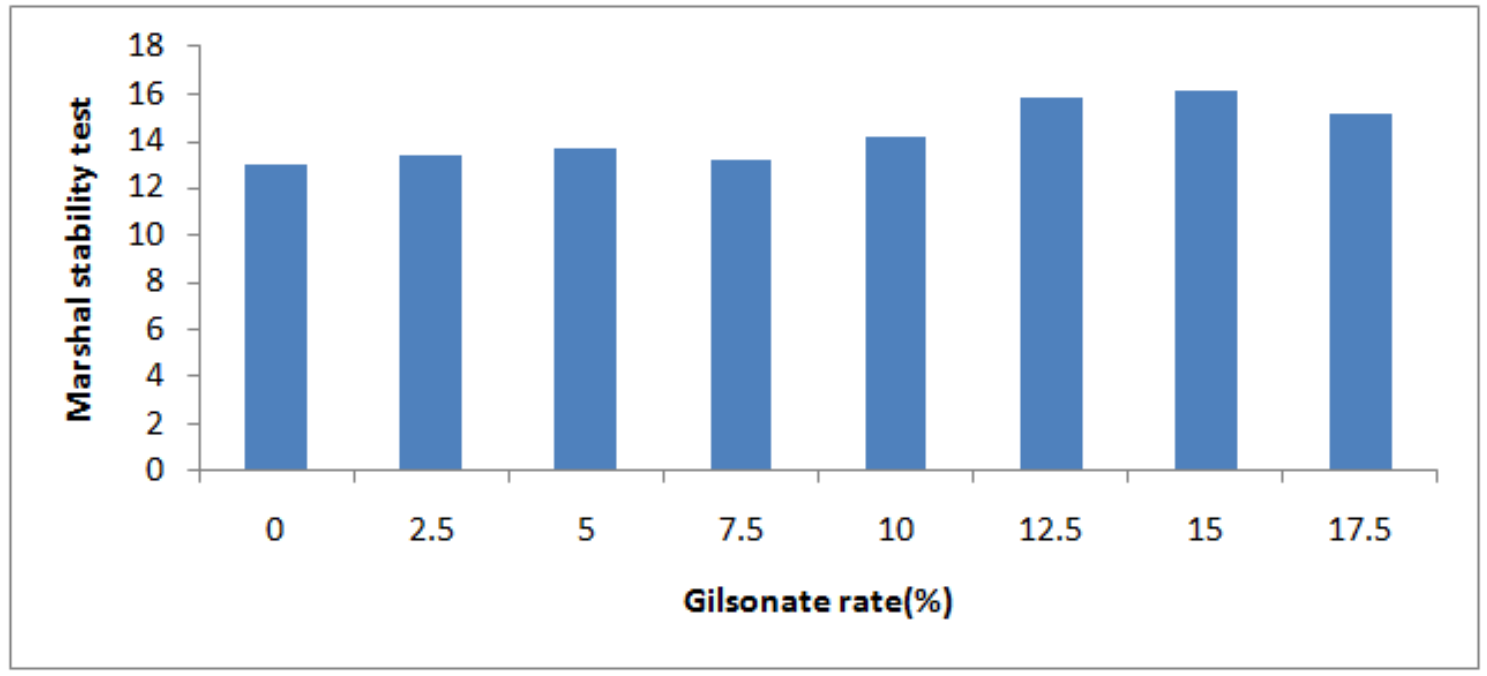

Figure 3: Variation of Marshall Stability with Gilsonite Content.

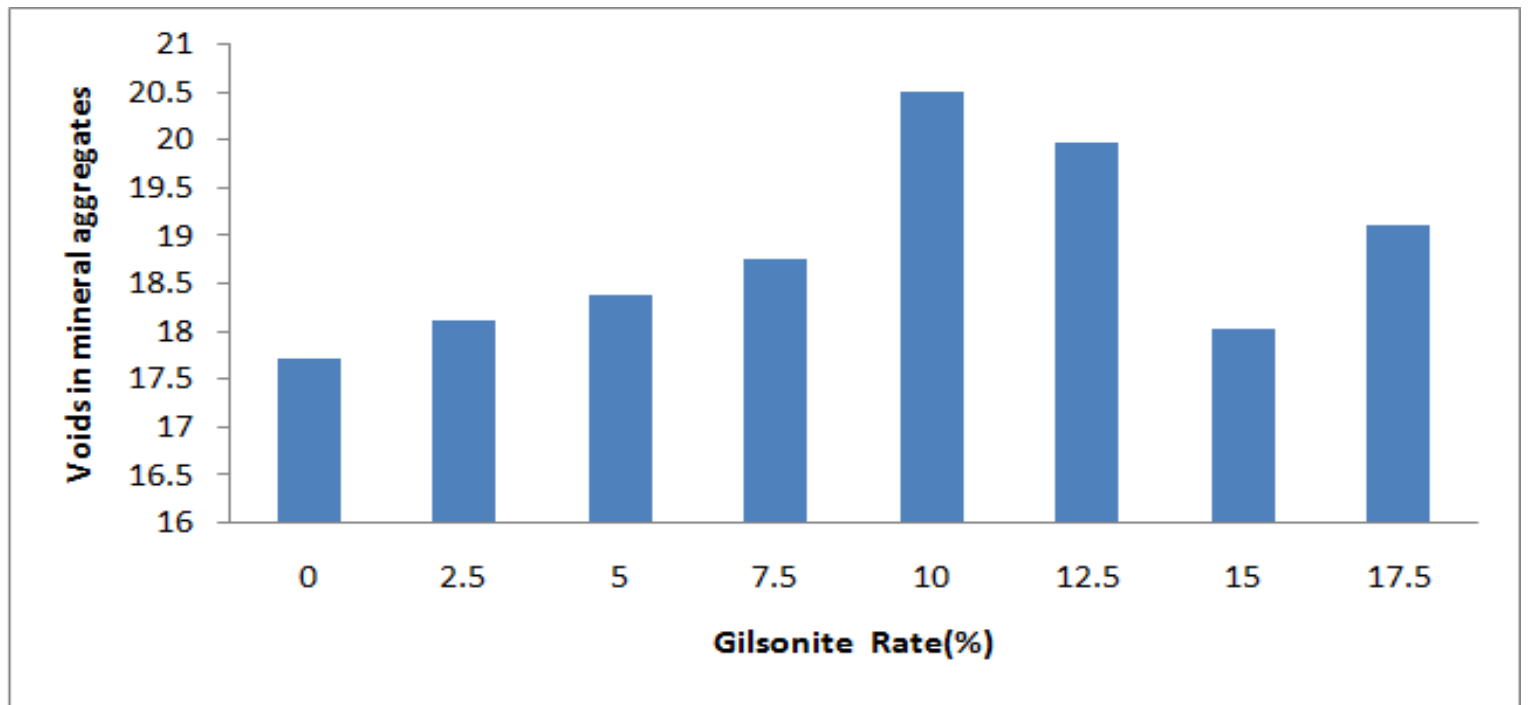

Figure 4: Variation of Voids in Mineral Aggregates with Gilsonite Content.

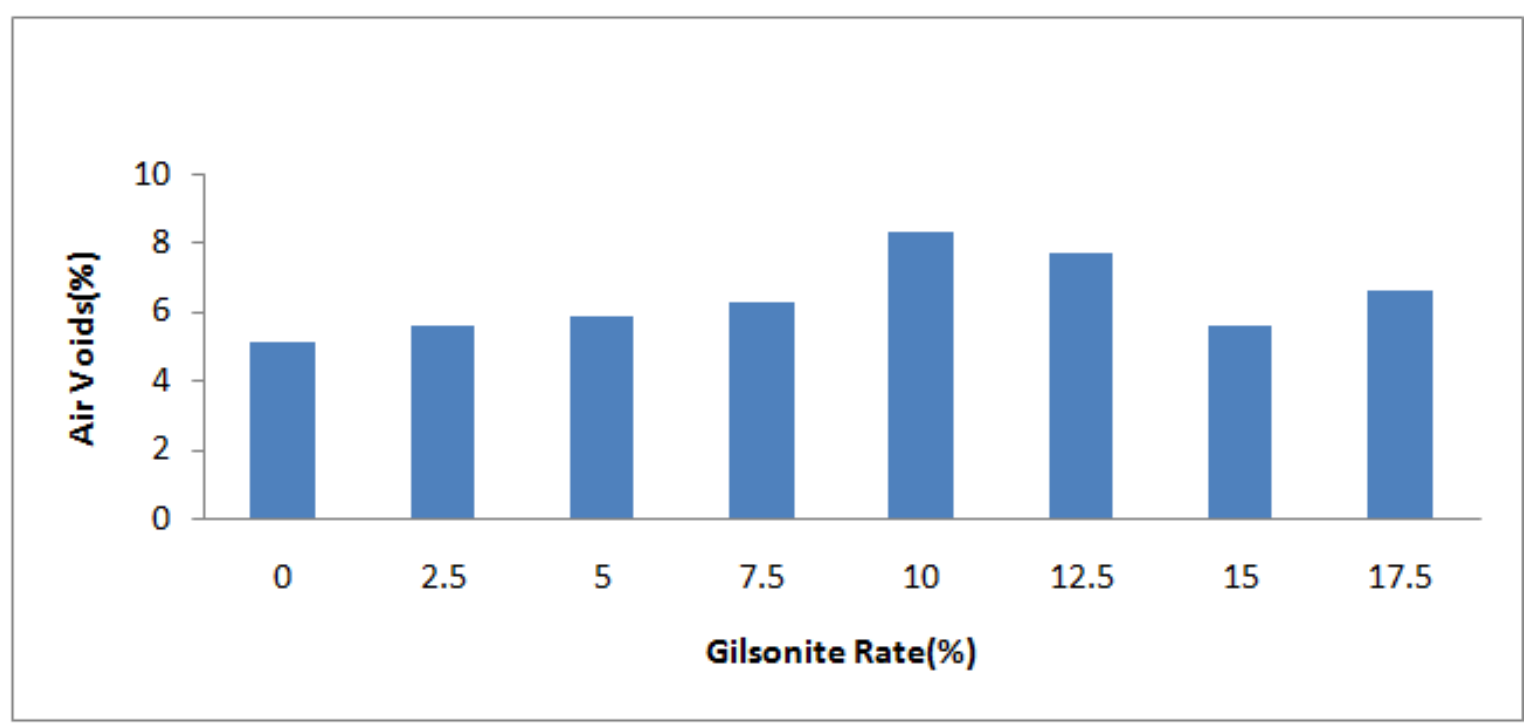

Figure 5: Variation of Air Voids Percent with Gilsonite Content. 


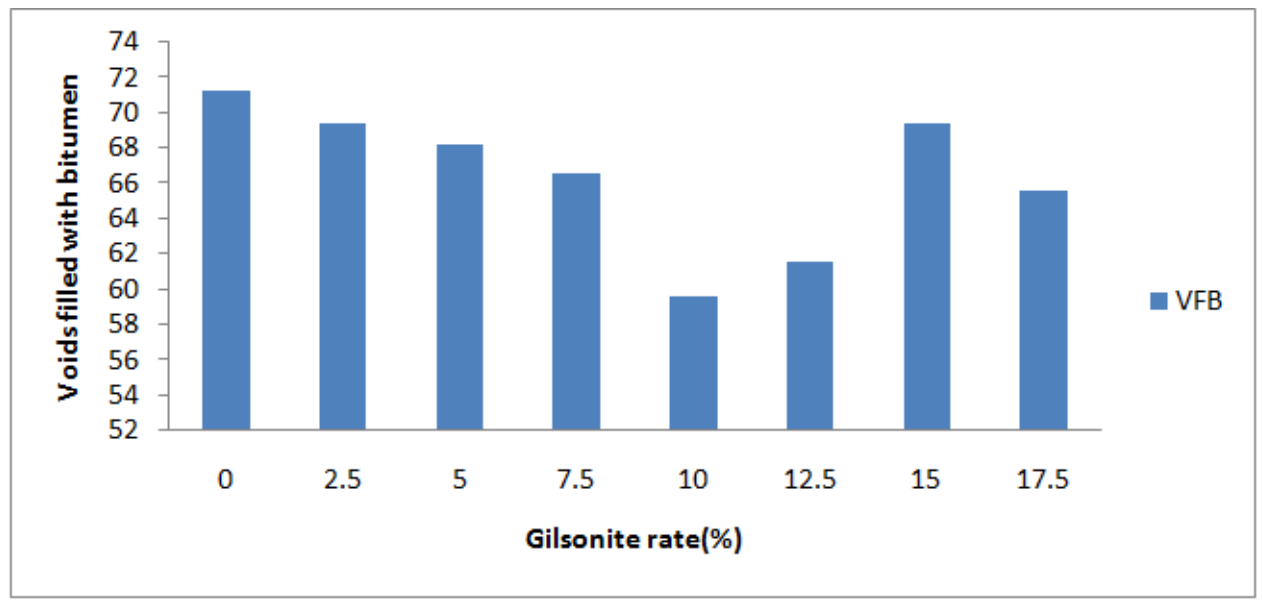

Figure 6: Variation of Voids Filled by Bitumen with Gilsonite Content.

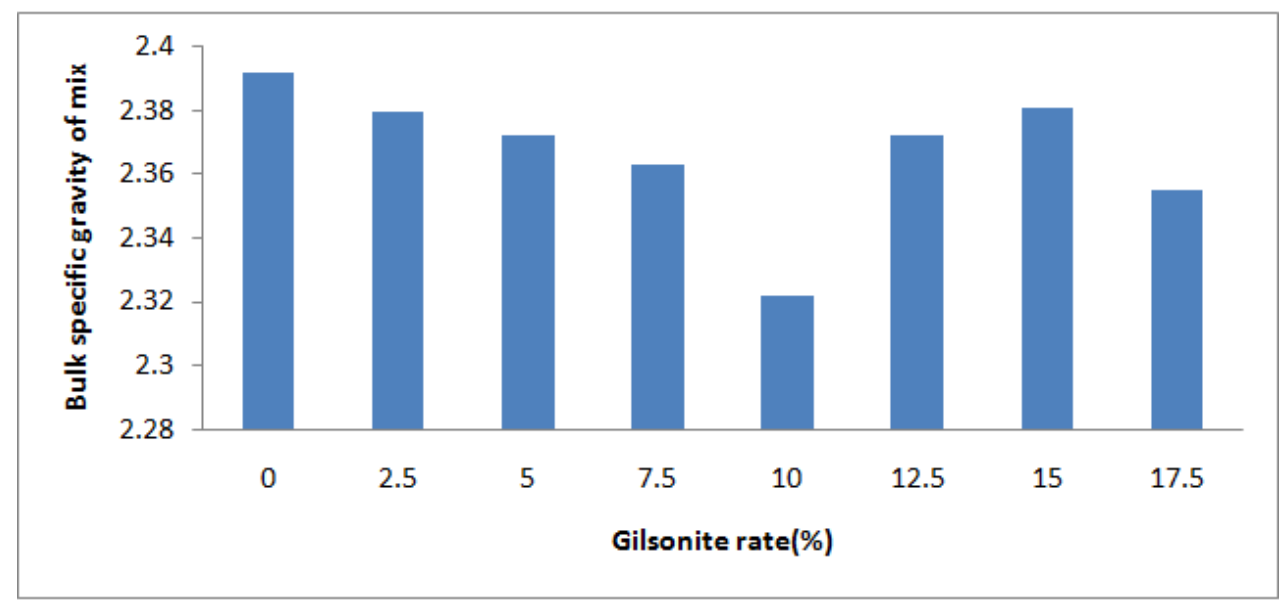

Figure 7: Variation of Bulk Specific Gravity of Mix with Gilsonite Content.

\section{CONCLUSIONS}

From the analysis of the results obtained, it has been found that the optimum Gilsonite content for the materials with a max nominal size of $12.5 \mathrm{~mm}$ is $15 \%$ of optimum bitumen content by weight. An increase in the Gilsonite content leads to an increase in the Marshall Stability value and max Marshall Stability of $16.20 \mathrm{KN}$ is found at $15 \%$ of Gilsonite content.

It has been also observed that the values of voids filled by bitumen increase with the increase in Gilsonite content in the mix. The value of $70 \%$ VFB was found at $15 \%$ of Gilsonite content. With the increase in Gilsonite content, the percent air voids in the mix increase. This could be the reason for the decrease in the bulk specific gravity of the mix with the increase in the Gilsonite content. The minimum value of percent air voids is observed at $15 \%$ of Gilsonite content.

The bulk specific gravity and flow value of mix decrease with the increase in the Gilsonite content in the mix. The maximum flow value is observed for the conventional mix without Gilsonite and the minimum value is observed for $17.5 \%$ of Gilsonite content.

\section{REFERENCES}

1. Aliasghar A. M, NakhaeNaderi K, Taher M. A, Aflaki S "Gilsonite modified asphalt for use in pavement construction" American journal of engineering and applied sciences e-ISSN: 27411 Issue: 02-|April -2018. 
2. Anderson,D. A.,Maurer, D., Ramirez., Christensen, D. W., Marasteanu, M. O., and Mehta, Y. (1999). "Field performance of modified asphalt binders evaluated with Superpave test methods: 1-80 test project." Transportation Research Record, 1661, $60-68$.

3. Baha, V.K., Mehmet,Y., and Murat, G. (2011). "Evaluation of the high-temperature performance of SBS+ gilsonite- modified binder". Fuel, 90, 3039

4. Baha, V.K., Mehmet,Y., and Murat, G. (2011). "Evaluation of the high-temperature performance of SBS+ gilsonite- modified binder". Fuel, 90, 3039

5. Bindu, C. S., et al. "Performance evaluation of warm mix asphalt using natural rubber modified bitumen and cashew nut shell liquid." International Journal of Pavement Research and Technology 13.4 (2020): 442-453.

6. Deshpande, Neela, et al. "Experimental investigation on strength characteristics of concrete using tyre rubber as aggregates in concrete." International Journal of Applied Engineering Research and Development (IJAERD) 4.2 (2014): 97-108.

7. Hugo A. R. Quintana, Jesus A. H. Noguera, Carlos F. U. Bonells "Behaviour of Gilsonite modified hot mix asphalt by wet and dry processes"ASCE e-ISSN: 1943-5533 Volume: 10 Issue: 20| June -2015.

8. Houshmandi S. K, Tortem A “Examination of the possibility of using Gilsonite in hot mix asphalt concrete"Jordon journal of engineering e-ISSN: 176-184 Volume: 13 Issue: 01-|November -2019.

9. Johannian H. Shafabaksh GH, H. Divandari "Performance evaluation of hot mix asphalt containing bitumen modified with Gilsonite" Construction and Building Material e-ISSN: 156-164 Volume: 131 Issue: 14-|November -2014.

10. Krishnapriya, M. G. "Performance evaluation of natural rubber modified bituminous mixes." Int. J. Civ. Struct. Environ. Infrastruct. Eng. Res. Dev 5 (2015): 121-134.

11. Mehmet Yilmaz, Baha V. Kok, NecatiKuluglu "Effect of using asphaltite as filler on mechanical properties of hot mix asphalt" Construction and Building Material e-ISSN: 4279-4286 Volume: 02 Issue: 19| May -2011.

12. M. Ameri, A. Mansourian, Amir H. Sheikhmotevali "Investigation effects of ethylene-vinyl acetate and Gilsonite modifiers upon the performance of base bitumen using superpave tests methodology" Construction and Building Material e-ISSN: 10011007 Volume: 36 Issue: $31 \mid$ July -2012.

13. Mahmoud, A., Ahmad, M., Saad, S.A., and Golazin, Y. (2011). "Technical study on the Iranian gilsonite as an additive for modification of asphalt binders used in pavement construction". Construction and Building Materials, 25, 1379-1387.

14. Mirzaiyan D, Amer M, Sabouri S, Nourouzi A "Evaluation of the performance and temperature susceptibility of Gilsonite and Styrene butadiene styrene modified asphalt binders” ELSEVIER e-ISSN: 679-692 Volume: 207 Issue: 21-|February -2019.

15. Nihat, M. (2013). "Investigation of usability of basalt fibers in hot mix asphalt concrete". Construction and Building Materials, 47, 175-180.

16. Pouria Hajikarimi, SassanAflaki, Alireza Sadat "Implementing fractional viscoelastic models to evaluate low-temperature characteristics of crumble rubber and Gilsonite modified asphalt binders" Construction and Building Material e-ISSN: 682687 Volume: 49 Issue: 25-|September -2013.

17. Suresh, B., N. Venkat Rao, and G. Srinath. "Evaluation of engineering properties of flexible Pavements using plaxis software." International journal of mechanical and production Engineering research and development (ijmperd) Issn (p) (2018): 2249-6890. 